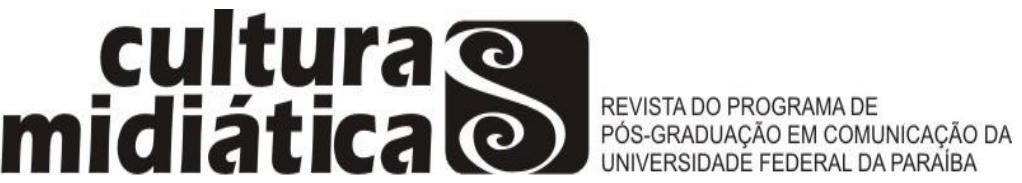

\section{Mecânicas de videogames e seu papel nos processos de significação a partir da experiência lúdica}

\author{
Videogame mechanics and their role on the meaning processes \\ from the playing experience
}

\author{
Raphael Vieira PIRES ${ }^{1}$ \\ Francisco José Paoliello PIMENTA ${ }^{2}$
}

\section{Resumo}

As mecânicas são os meios pelos quais os jogadores irão interagir com as estruturas formais dos jogos e também com seu mundo ficcional. Neste sentido, este artigo busca compreender melhor como os processos comunicacionais entre a realidade material do jogador e as regras do jogo estão imbricadas nas experiências de jogabilidade e de que forma as mecânicas "filtram" as mensagens enviadas nessa comunicação, participa na produção das semioses, como processos de significação, e atua como representações de atividades e objetos fora do universo do jogo. Para isso, vamos buscar por conceitos clássicos e contemporâneos de jogos e videogames a fim de entender o papel das mecânicas na construção de sentido e ancorar nossas descobertas a partir de exemplos extraídos de videogames analisados.

Palavras-chave: Videogames. Mecânicas de jogo. Significação. Materialidade.

\begin{abstract}
Game mechanics are the means by which players will interact with the formal structures of games and, in the case of videogames, also with its fictional world. In this sense, this article aims to better understand how the communication processes between the material reality of the player and the game rules are embedded on gameplay experiences and in what way the game mechanics "filter" the messages sent in this communication, participate in the production of the game's semiosis and act as representations of activities and objects outside the game's universe. For this purpose, we will search for classical and contemporary game and videogame concepts in order to comprehend the role of the mechanics in constructing meaning and we will also link our findings from examples extracted from analyzed videogames.
\end{abstract}

Keywords: Videogames. Game mechanics. Meaning. Materiality.

\footnotetext{
${ }^{1}$ Mestrando do Programa de Pós-Graduação em Comunicação da Universidade Federal de Juiz de Fora (UFJF). E-mail: raphavpires@gmail.com

${ }^{2}$ Professor Doutor do Programa de Pós-Graduação em Comunicação da Universidade Federal de Juiz de Fora (UFJF). E-mail: paoliello@acessa.com
}

Ano X, n. 19 - jul-dez/2017 - ISSN 1983-5930 - http://periodicos.ufpb.br/ojs2/index.php/cm 


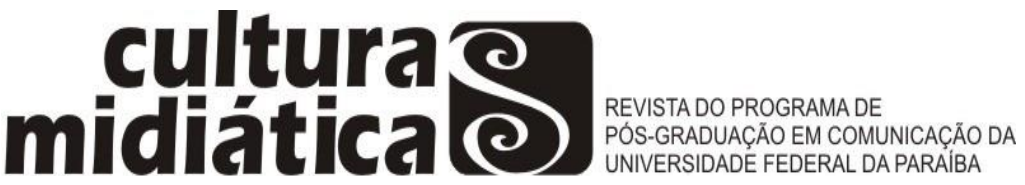

\section{Introdução}

Videogames são paradoxais: ao mesmo tempo que promovem diversão e entretenimento, fazem isso por meio de sucessivas tentativas de frustrar os esforços do jogador, que, quando inserido dentro do jogo, tem o mundo inteiro literalmente contra si. Os desafios são diversos: são inimigos atacando, a necessidade de encontrar aliados, a urgência da exploração do mapa, estratégias, contra-ataques, entre tantas outras possibilidades. Mas é nesse mesmo mundo que serão encontradas todas as ferramentas e respostas para os desafios propostos.

Podemos dizer que essas ferramentas dadas ao jogador são as mecânicas de jogo. É por meio delas que ele irá interagir com seu universo e suas regras. No desenvolvimento de jogos, chamamos de game design o processo pelo qual as mecânicas e as regras são definidas, e de level design a aplicação prática desses elementos (SALEN e ZIMMERMAN, 2004; KREMERS, 2009). Katie Salen e Eric Zimmerman tratam o game design como a criação da jogabilidade significativa (meaningful play), ou seja, criar, a partir do processo lúdico, experiências com significados para os usuários. E essas experiências recheadas de significados são vivenciadas por meio das mecânicas.

Elas são os meios pelos quais os jogadores interpretam os ambientes virtuais dos jogos digitais e agem sobre eles, além de se portarem como ferramentas materiais e cognitivas para que o jogador possa entender o ambiente em que está inserido, interpretálo, significá-lo e tomar o seu lugar nesse processo comunicacional. Em outras palavras, as mecânicas ditam as formas como as diversas linguagens imagéticas e textuais dos games carregarão seus significados e como elas irão se relacionar com o contexto sociocultural em que estão conectadas.

Com isso, tem-se que o gameplay é o aspecto mais importante de um jogo, no que concerne à sua capacidade única de transmitir mensagens. O gameplay é uma lógica que se expressa verbalmente com sons e imagens, dando início a um processo circular de pergunta (desafio proposto) e resposta (o ato de jogar).

Sendo assim, de que forma as mecânicas carregam mensagens do jogo para o jogador e do jogador para o jogo? Ou, mais importante, de que maneira elas influenciam as mensagens veiculadas pelo game? 


\section{midiäticale}

Para tentar responder essas questões e lançar luz sobre os aspectos significativos inerentes aos jogos, realizaremos uma breve revisão dos principais conceitos elaborados nos últimos anos e delimitar o lugar do videogame dentro desse arcabouço teórico. Após esse levantamento inicial, vamos aprofundar nossa discussão a respeito de mecânicas como condicionantes das semioses do jogo, diretamente ligadas à materialidade das experiências lúdicas, e também como representações do mundo externo a elas, buscando por exemplos retirados de títulos de diversas épocas e ancorando nossas descobertas em noções já trabalhadas por pesquisadores da área.

\section{O jogo e o videogame}

Vários autores se lançaram no desafio de delimitar o que é jogo e suas relações com os jogadores e com o mundo externo. As definições, apesar de utilizarem conceitos e aproximações distintas, possuem mais similaridades que discrepâncias. Jesper Juul (2003), um dos mais influentes pesquisadores da área, realizou um extenso trabalho bibliográfico sobre como esses artefatos foram conceituados ao longo da história pelos estudiosos Huizinga, Caillois, Bernard Suits, Avedon \& Sutton-Smith, David Kelley, Chris Crawford e Salen \& Zimmerman, conforme quadro abaixo:

Quadro 1

\begin{tabular}{|l|l|}
\hline \multicolumn{1}{|c|}{ FONTE } & \multicolumn{1}{c|}{ DEFINIÇÃO } \\
\hline $\begin{array}{l}\text { Johan Huizinga } \\
\text { (1950, p.13) }\end{array}$ & $\begin{array}{l}\text { “... uma atividade livre, conscientemente tomada como 'não-séria' e } \\
\text { exterior à vida habitual, mas ao mesmo tempo capaz de absorver o } \\
\text { jogador de maneira intensa e total. É uma atividade desligada de todo e } \\
\text { qualquer interesse material, com a qual não se pode obter qualquer lucro, } \\
\text { praticada dentro de limites espaciais e temporais próprios, segundo uma } \\
\text { certa ordem e certas regras. Promove a formação de grupos sociais com } \\
\text { tendência a rodearem-se de segredos e sublinharem sua diferença em } \\
\text { relação ao resto do mundo por meio de disfarces ou outros meios } \\
\text { semelhantes”. }\end{array}$ \\
\hline $\begin{array}{l}\text { Roger Caillois } \\
(1961, \text { p. 10-11) }\end{array}$ & $\begin{array}{l}\text { "[o jogo] é uma atividade que é essencialmente: livre (voluntária), } \\
\text { separada (no tempo e espaço), incerta, improdutiva, governada por regras, } \\
\text { fictícia (faz-de-conta)”. }\end{array}$ \\
\hline $\begin{array}{l}\text { Bernard Suits } \\
(1978, \text { p. 34) }\end{array}$ & $\begin{array}{l}\text { "Jogar um jogo é se engajar em uma atividade dirigida para causar um } \\
\text { estado específico de ocorrências, usando somente meios permitidos por } \\
\text { regras, onde as regras proíbem meios mais eficientes em favor de meios } \\
\text { menos eficientes, e onde tais regras são aceitas apenas porque elas tornam }\end{array}$ \\
\hline
\end{tabular}




\section{cylturae midiática@

\begin{tabular}{|l|l|} 
& possível tal atividade". \\
\hline $\begin{array}{l}\text { Avedon \& } \\
\text { Sutton-Smith } \\
\text { (1981, p. 7) }\end{array}$ & $\begin{array}{l}\text { "No seu nível mais elementar, podemos definir jogo como um exercício } \\
\text { de sistemas de controle voluntário, nos quais há uma oposição entre } \\
\text { forças, confinado por um procedimento e regras, a fim de produzir um } \\
\text { resultado não estável". }\end{array}$ \\
\hline $\begin{array}{l}\text { Chris Crawford } \\
\text { (1981, capítulo 2) }\end{array}$ & $\begin{array}{l}\text { "Eu percebo quatro fatores comuns: representação [um sistema formal } \\
\text { fechado, que subjetivamente representa um recorte da realidade] } \\
\text { interação, conflito e segurança [o resultado do jogo é sempre menos } \\
\text { severo do que as situações que o jogo modela]". }\end{array}$ \\
\hline $\begin{array}{l}\text { David Kelley } \\
(1988, \text { p. 50) }\end{array}$ & $\begin{array}{l}\text { "Um jogo é uma forma de recreação constituída por um conjunto de } \\
\text { regras que especificam um objeto (objetivo) a ser almejado e os meios } \\
\text { permissíveis para consegui-lo". }\end{array}$ \\
\hline $\begin{array}{l}\text { Salen \& } \\
\text { Zimmerman } \\
(2003, \text { p. 96) }\end{array}$ & $\begin{array}{l}\text { "Um jogo é um sistema no qual jogadores engajam-se em um conflito } \\
\text { artificial, definido por regras, que resultam em um resultado } \\
\text { quantificável". }\end{array}$ \\
\hline
\end{tabular}

Fonte: (RANHEL, 2009, p. 10, adaptado)

Então, a partir das confluências e discrepâncias desses pontos de vista, Juul chega a um resumo abarcando seis pontos. Jogos teriam sempre, portanto: 1) regras, 2) resultados variáveis e quantificáveis, 3) valores atribuídos aos potenciais resultados, 4) esforço do jogador, 5) vínculo do jogador ao resultado, 6) consequências negociáveis. Com isso, o autor chega a seguinte definição:

Um jogo é um sistema formal baseado em regras com resultados variáveis e quantificáveis, onde diferentes resultados estão vinculados a diferentes valores, o jogador exerce esforço com o objetivo de influenciar os resultados, o jogador sente-se vinculado a este resultado, e as consequências da atividade são opcionais e negociáveis. ${ }^{3}$ (JUUL, 2003, p.1, tradução livre)

Na sequência, a partir de três relações (jogos/sistemas formais, jogador/jogo e jogo/mundo externo), Juul desenha um diagrama no qual mapeia diferentes atividades lúdicas dentro de seu esquema conceitual. O resultado é um desenho de círculos concêntricos onde na parte mais interna estariam os jogos, seguido do círculo onde estariam os quase-jogos e, mais externamente, atividades que não seriam jogos. $\mathrm{O}$

3 A game is a rule-based formal system with a variable and quantifiable outcome, where different outcomes are assigned different values, the player exerts effort in order to influence the outcome, the player feels attached to the outcome, and the consequences of the activity are optional and negotiable.

Ano X, n. 19 - jul-dez/2017 - ISSN 1983-5930 - http://periodicos.ufpb.br/ojs2/index.php/cm 


\section{midiäticales}

critério de classificação estabelecido por Juul considera jogos as atividades que apresentam todas as seis características propostas por ele e como quase-jogos ou nãojogos qualquer prática que falte com pelo menos uma delas. Por exemplo, RPGs em lápis e papel são, de acordo com o diagrama, quase-jogos por não apresentarem regras fixas e brincadeiras de roda não são jogos, pois não tem resultados variáveis, valorização destes resultados, esforços do jogador vinculados aos resultados e consequências negociáveis.

A classificação de Juul problematiza ainda mais a definição do que é jogo, principalmente quando ancorado em um sistema computacional. Muitos videogames cairiam no círculo do quase-jogo por não apresentarem todas as qualidades colocadas. Nesse caso, SimCity (1989), por exemplo, não apresenta objetivos explícitos, portanto não tem valores atribuídos a resultados possíveis.

Portanto, de acordo com Juul, uma parte do que se entende culturalmente por videogames não seriam jogos completos em si, mas sim experiências lúdicas de diversas naturezas. A consequência deste estudo e sua aplicação aos videogames é o distanciamento dos jogos clássicos em relação a sua contrapartida eletrônica. Esta última teria um leque de atuação muito mais amplo, com hibridizações de outras mídias e suportes (cinema, vídeo, literatura, hipertexto etc) e diferentes linguagens, tendo como denominador comum o meio digital/numérico.

De fato, posteriormente Juul (2005) classificará videogames como parcialmente reais (half-real), pois são a junção de regras reais, às quais os jogadores irão se vincular e agir sobre, com mundos ficcionais, criados a partir do processamento gráfico dos computadores. Apesar de todo tipo de jogo, seja analógico ou eletrônico, contar com aspectos ficcionais em sua estrutura, videogames têm uma maior capacidade de projetar esses mundos ficcionais, criando universos muito mais sensíveis, elaborados e concretos, onde a imersão tem papel central na jogabilidade. Segundo o autor,

Estas são as duas coisas que constituem os videogames: regras reais e mundos ficcionais. Ao conceber mundos ficcionais, videogames se afastam de jogos tradicionais não-eletrônicos, que são, na sua maior parte, abstratos. E isso é parte da inovação dos videogames. A interação entre as regras do jogo e a ficção é uma das características mais importantes dos videogames (...). Esta interação está presente em muitos aspectos de jogos: no design dos próprios jogos; no modo como 


\section{midiäticales}

percebemos e usamos jogos; e na maneira como discutimos jogos ${ }^{4}$. (JUUL, 2005, p. 12-13, tradução livre)

Nesse sentido, as mecânicas em videogames, além de terem o papel de conectar material e cognitivamente o jogador às regras, também delimitam e organizam o modo como ele perceberá os signos do mundo ficcional no qual está imerso.

\section{Mecânicas e significação}

A mudança de mecânicas de jogo iniciada por Resident Evil 4 (2005) na famosa série de videogames japonesa foi feita principalmente com relação ao posicionamento da câmera e melhor manejo da mira. Vale notar que controles mais avançados e ergonômicos de consoles com maior poderio gráfico, como o GameCube e PlayStation 2 abriram caminho para essas novas mecânicas, que permitiram um melhor mapeamento dos cenários. Com isso, puzzles de maior complexidade visual foram colocadas em prática e a maneira como os jogadores começaram a perceber os elementos do mundo ficcional, relacioná-los às regras (objetivos) e produzir significados mudou.

Em Pacman (1980) as mecânicas são a movimentação do personagem em quatro direções pelo labirinto, com velocidade maior que os inimigos e a possibilidade de adquirir poderes temporários para incapacitar (também por um breve período) os antagonistas. É somente por meio dessas ferramentas que o objetivo será alcançado, pois as mecânicas são parte integrante da estrutura formal dos jogos, seu conjunto de regras. No caso de Pacman, o objetivo é coletar todas as pastilhas no labirinto antes de ser atacado por um dos quatro fantasmas que rondam o cenário. E essa meta só será alcançada se a comunicação com as mecânicas for realizada de maneira efetiva.

Da mesma maneira, a narrativa e a ficção do jogo acontecem de forma a se encaixar logicamente a essas mecânicas. Dois títulos que tratam do mesmo tema e contexto histórico (no caso abaixo, a Segunda Guerra Mundial), mas que possuem

\footnotetext{
4 These are the two things that video games are made of: real rules and fictional worlds. In having fictional worlds, video games deviate from traditional nonelectronic games that are mostly abstract,' and this is part of the newness of video games. The interaction between game rules and game fiction is one of the most important features of videogames (...). Their interaction is present in many aspects of games: in the design of the games themselves; in the way we perceive and use games; and in the way we discuss games.
}

Ano X, n. 19 - jul-dez/2017 - ISSN 1983-5930 - http://periodicos.ufpb.br/ojs2/index.php/cm 


\section{midiäticale}

jogabilidades distintas, como Commandos (1998) e Battlefield 1942 (2002) produzirão interpretações diferentes no ato de jogar, pois os processos de significação de um jogo estão diretamente ligados às suas mecânicas. Commandos possui uma jogabilidade estratégica voltada para espionagem, stealth e controle de vários personagens ao mesmo tempo, enquanto Battlefield 1942 exige uma boa percepção de tempo e espaço em um ambiente com ritmo acelerado, além de boa comunicação com companheiros em partidas multiplayer.

Apesar dos elementos visuais e sonoros dos dois exemplos citados serem muito semelhantes e estarem conectados ao mesmo domínio semiótico da Segunda Guerra Mundial, a diferença nas mecânicas guiará a atenção do jogador para signos diferentes. Uma arma no chão perto de um soldado inimigo, por exemplo, causará reações cognitivas e materiais divergentes, pois seus significados dentro das estruturas formais de regras e objetivos não são os mesmos. Da mesma forma, a percepção sobre o que seria estar na pele de um soldado na Segunda Guerra Mundial e quais os sentimentos e entendimentos ligados a essa prática se conectam ao modo como cada elemento desse ambiente chega à mente do jogador.

As mecânicas são criadas pelo game designer e são limitadas (regidas) pelo seu próprio sistema formal. Ao passo que é o jogador quem age no jogo a partir de sua própria vontade e de suas próprias habilidades, essa interação está condicionada pelas mecânicas desenvolvidas pelo designer. E essa característica é primordial para começarmos a analisar qual o papel das mecânicas de gameplay na produção de significados. Chris Swain diz o seguinte sobre a singularidade das estruturas lúdicas como meios veiculadores de mensagens:

Qualquer mídia, por meio de suas particularidades estruturais, tem um grande efeito na forma com que suas mensagens transmitidas são entendidas (...) O impresso é diferente da televisão, que é diferente do filme, que é diferente do hipertexto, que é diferente dos jogos. Quer dizer, a estrutura interativa dos games, baseada em metas, afeta grandemente como as mensagens que estão incorporadas nos jogos são entendidas pelos usuários. (SWAIN, 2010, p. 217-218, tradução livre) ${ }^{5}$

5 Any given medium, by its structural particulars, has a large effect on how the messages conveyed through it are understood. (...) Print is different from television, which is different from film, which is different from hypertext, which is different from games. That is, the interactive, goals-based structure of games greatly affects how messages that are embedded in games are understood by users.

Ano X, n. 19 - jul-dez/2017 - ISSN 1983-5930 - http://periodicos.ufpb.br/ojs2/index.php/cm 


\section{midiätica@e}

Fala-se, inclusive, que o jogo só faz sentido quando jogado (KREMERS, 2009; JUUL, 2013; MENDES, 2006). O jogador precisa interpretar os diversos signos do ambiente a fim de configurar suas ações em concordância com seus objetivos, de forma que estar em uma situação de jogo seja estar imerso em "uma combinação de fins, meios, regras, equipamentos e ações manipulativas" " (ESKELINEN, 2004, p.38, tradução livre). Ou seja, o modo pelo qual o usuário tem de entender e agir sobre as mensagens produzidas pelo game necessita de movimentos (input ou reação) por parte do jogador para produzir significados.

\section{Mecânicas e materialidade}

Essas mecânicas também têm relação direta com a materialidade de cada videogame. Mesmo que o jogo eletrônico e suas regras funcionem em uma lógica própria daquele universo ficcional, todas as ações do jogador que gerarão significados são iniciadas a partir da interação do usuário com interfaces físicas. Com a volta dos jogos em Realidade Virtual (RV) nos últimos anos e sua crescente popularização, algumas novas mecânicas estão sendo implantadas para dar conta das possibilidades e limitações desse suporte, por exemplo.

Duas produções lançadas recentemente para consoles e computadores estão com versões em realidade virtual em desenvolvimento, Doom VR e Fallout 4 VR. Com alta capacidade imersiva, esses jogos inserem o movimento da cabeça como uma das mecânicas; agora é possível olhar para algum lugar do cenário enquanto suas mãos apontam em outra direção e se ocupam de outra tarefa. No entanto, jogos em RV ainda possuem algumas limitações e problemas, como menor número de botões de ação e a ocorrência de náuseas e tontura em diversas pessoas por conta das discrepâncias ocorridas entre as estimulações sensórias recebidas pelo sistema visual e vestibular, similar ao que ocorre em simulações de voo ou em viagens de carro (KOLASINSKI, 1995).

Como uma das medidas para sanar esse problema, desenvolvedores estão introduzindo mecânicas de movimentação no espaço virtual baseadas em teletransporte, diminuindo o impacto da sensação ilusória de deslocamento percebida pelo corpo do

6 (...) as a combination of ends, means, rules, equipment, and manipulative action.

Ano X, n. 19 - jul-dez/2017 - ISSN 1983-5930 - http://periodicos.ufpb.br/ojs2/index.php/cm 


\title{
midiäticale
}

jogador, o que muda totalmente a experiência de jogo e como vamos perceber e interpretar os signos dos cenários. Jogar o Doom (2016) original e sua versão em RV serão experiências que produzirão semioses diferentes, pois algumas das mecânicas sofreram mudanças. Isso ocorre uma vez que as mecânicas são interdependentes dos objetivos do jogo (suas regras) e de aspectos materiais (dispositivo, controle de botões, tamanho da tela, local ou online etc).

De fato, a indústria dos games é uma das principais propulsoras do desenvolvimento de equipamentos e hardwares para gerar novas interações do corpo do usuário com o computador. Videogames se mantém no limiar do estado da arte das capacidades interacionais do computador, expandindo as fronteiras das possibilidades de uso e ergonomia dos dispositivos computacionais. O livro Racing the Beam: The Atari Video Computer System, de Nick Montfort e Ian Bogost inaugurou o que ficou conhecido como platform studies, uma abordagem em que as plataformas ganham atenção central para se analisar o design de jogos e a experiência do jogador. Na obra, os autores relatam como o modo de produção, o design e as limitações técnicas do console Atari 2600, lançado em 1977 nos EUA e em 1983 no Brasil, mantêm relação direta com o desenvolvimento de games para esta plataforma e os tipos de mecânicas possíveis de serem inseridas.

\begin{abstract}
Assim, o projeto de Montfort e Bogost (2009) centra-se inteiramente na reflexão sobre a relação entre o computador e as camadas culturais examinando como os limites computacionais materiais da plataforma moldam e influenciam as decisões de concepção e consequentemente a experiência do jogador. Através desta análise, Montfort e Bogost destacam como particulares convenções genéricas e estéticas surgiram em relação a essas considerações históricas. (APPERLEY \& JAYEMANE, 2017, p. 8)
\end{abstract}

Nessa mesma linha sobre a importância das materialidades para o ato de jogar, inovações que vieram com o console Wii e com os apetrechos Kinect e Playstation Move expandiram o significado do uso do corpo dentro do universo do game e novas mecânicas foram inseridas para dar conta dessas contingências.

Os recentes desenvolvimentos na indústria de jogos - Wii, PlayStation Move e Microsoft Kinect - re-enfatizam o papel do corpo em jogo. Como Simon (2009) aponta, o Wii (e as plataformas de jogos de movimento em geral) torna o corpo espetacular: parte do prazer dessas 


\section{midiäticales}

plataformas vem de assistir corpos em jogo. A materialidade da experiência corporativa do jogo baseado em movimento foi um grande ponto de venda para o Wii, o que ajudou a Nintendo a mudar as unidades para uma nova demografia através da promoção bem sucedida do Wii Fit (NINTENDO EAD, 2008) e Wii Fit Plus (NINTENDO EAD, 2009). Os jogos digitais, então, também moldam e transformam nossos corpos e percepções. (APPERLEY \& JAYEMANE, 2017, p. 17)

Cada experiência individual com sessões de jogo, mediadas por mecânicas, têm relação direta com a condição do local onde ela acontece, e isso se verifica também no papel desempenhado pelos aparatos físicos usados para o contato entre a realidade material do interator e o ambiente ficcional em questão. Dessa mesma forma, videogames e seus modos de ação integram-se ao mundo externo da qual fazem parte como artefatos culturais, podendo atuar, nesse sentido, como alegorias da sociedade em que estão inseridos.

\section{Alegoria e representação}

Até aqui vimos como as mecânicas funcionam como um canal de comunicação entre a realidade material do jogador e a estrutura formal de regras em que está imerso. Além dessas relações, no entanto, as mecânicas também podem fazer referência a objetos e fenômenos do mundo externo ao jogo. Jogos e videogames, como artefatos construídos dentro de um contexto econômico, social e cultural, não são universos descolados da sua realidade material. Por isso, suas mecânicas, como modos de ação, podem nos colocar em contato com atividades que possam remeter, de forma crítica e criativa, a práticas exteriores a esse meio.

Janet Murray (2003), ao analisar as mecânicas de Tetris (1984), faz a seguinte analogia com a sociedade workaholic:

(...) em Tetris tudo o que você modela com perfeição é varrido para fora da tela. Ter sucesso significa apenas ser capaz de manter o fluxo. Esse jogo é uma encenação perfeita da vida sobrecarregada dos norteamericanos nos anos 90 - do constante bombardeio de tarefas que exigem nossa atenção e que devemos, de algum modo, encaixar em nossas agendas superlotadas, não sem antes limparmos a nossa mesa de trabalho a fim de abrir espaço para o próximo e violento assalto. (MURRAY, 2003, p. 142) 


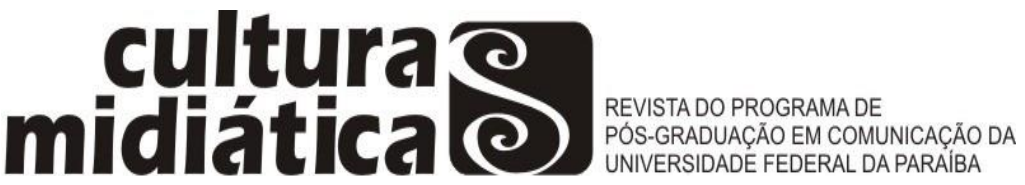

Aqui, pouco importa se Alexey Pajitnov, o desenvolvedor de Tetris, elaborou as mecânicas propositadamente para serem consideradas dessa maneira ou não, mas sim que "todo jogo pode potencialmente ser lido como uma alegoria de algo" (JUUL, 2005, p. 177).

Na mesma linha, Mckenzie Wark (2007) argumenta que jogos são alegorias do tempo e da sociedade na qual foram criadas. $O$ autor lança o neologismo "alegoritmo" (allegorithm) para dizer que o algoritmo do videogame (no qual as mecânicas estão imbricadas) é ele próprio uma alegoria do espaço e das condições que o influenciam. Videogames oferecem uma visão intuitiva ao jogador diante deste algoritmo apresentado (WARK, 2007) e, por isso, tem a capacidade de oferecer versões utópicas da condição humana em tempos onde as programações dos softwares intervêm em nossa forma de agir e pensar (FLUSSER, 2007).

Ao passo que videogames se tornam cada vez mais perfeitos, com sistemas mais elaborados e mundos virtuais detalhando toda a vontade utópica humana, o cotidiano no mundo atual (o qual Wark chama de gamespace) continua a decair em uma série de jogos imperfeitos, injustos e ilusórios (WARK, 2007). Com isso, este mundo em decadência dá lugar para o surgimento de uma nova persona, o gamer como um teórico (gamer as a theorist), que irá sempre questionar a situação precária a que está submetido no gamespace, um local construído a partir de estruturas falhas, onde a criatividade lúdica se torna parte do trabalho alienado e nada pode escapar de seu espetáculo.

Wark faz um extenso ensaio sobre o videogame Katamari Damacy (2004) e estabelece duas interessantes conexões com objetos exteriores ao contexto do game: o mito de Sísifo e o trabalho alienado. Em Katamari Damacy, o jogador encarna a tarefa de um príncipe que deve controlar uma bola extremamente adesiva (chamada de katamari) que coleta todo e qualquer item ou objeto do cenário que seja menor que ela, tudo isso com o intuito de reconstruir estrelas e planetas destruídos acidentalmente por seu pai, uma entidade celestial e com tamanho maior que de um planeta. Começa-se coletando pequenos objetos e, a medida que mais itens vão sendo reunidos, pode-se chegar à dimensão de uma constelação de estrelas.

O autor, então, faz um paralelo entre os movimentos realizados pelo jogador e a tarefa tétrica e infinita de Sísifo, que, de acordo com o mito, foi punido pelos deuses 


\title{
midiäticales
}

gregos com a incumbência de carregar uma pesada rocha montanha acima apenas para vê-la rolar abaixo para começar tudo novamente.

\begin{abstract}
Onde está Sísifo agora? Usando o controlador analógico no controle do jogo (...) Para mover a bola, você gira os pequenos joysticks analógicos. Empurre o direcional para frente e o personagem rola a bola para frente. Puxe o direcional para trás e o personagem rola a bola de volta. Vire para a esquerda, vire para a direita - parece até que a variação de pressão do dedo no controlador se traduz em movimentos variáveis. Isto é analógico - uma relação de variação contínua. Só que não, realmente. É um jogo digital. O jogo converte o movimento contínuo de seus dedos nos direcionais em códigos digitais. Ele transforma movimentos em decisões. (WARK, 2007, p. 72-73)
\end{abstract}

Dessa forma, os movimentos reais do jogador, traduzidos em códigos binários dentro do universo do jogo em formato de uma bola em uma tarefa sem sentido e improdutiva assemelha-se ao encargo de Sísifo, que é, por sua vez "o trabalho/labor de todos nós: insípido, repetitivo, infinito, um esforço descomunal sem futuro certo" (WARK, 2007, p. 72). As mecânicas em Katamari Damacy são, para Wark, uma alegoria da neurose social que coloca a humanidade em um ciclo de atividades repetitivas e hipnóticas para atender obedientemente as demandas de uma entidade incongruente e ilusória, o gamespace.

Por sua vez, o pesquisador de jogos Ian Bogost (2007) afirma que todo e qualquer jogo lança mão, dentro de seus esquemas de regras e mecânicas, de algum tipo de enquadramento ideológico. Para o autor, o próprio esquema de regras e as mecânicas estão carregadas de signos e o processo de interpretação dessas mensagens acontece pelo ato de jogar.

Bogost oferece um exemplo de como as mecânicas podem carregar mensagens de cunho político (BOGOST, 2006). No jogo Vigilance 1.0 (2000), do artista francês Martin Le Chevallier, somos levados a procurar e combater delitos e ocorrências como prostituição e vagabundagem por meio de um sistema de segurança em vídeo. A primeira vista, o jogo parece reforçar a ideia de vigilância como garantia de um mundo puro, mas ao oferecer recompensas por cada crime detectado, nos vemos imersos em nossa própria perversão, a vigilância sem limites. O jogador torna-se mais depravado quanto aqueles que tinha de combater. As mecânicas foram capazes de veicular essas informações por meio do processo lúdico no qual o jogador estava imerso. 


\section{midiätica@e}

\section{Considerações finais}

O jogo é um processo experiencial, formatado dentro de uma estrutura formal de regras, cuja lógica remete, em última instância, aos objetivos finais desse mesmo jogo. Esses objetivos são, usualmente, a resolução de todos os desafios propostos, da maneira mais eficiente e completa possível. Assim, as mecânicas, por serem os modos de ação disponíveis para que o jogador possa interagir com o universo lúdico que está imerso, são um elemento central para a geração de significados e interpretações. Uma vez que elas funcionam como ponto de contato entre game e jogador, as mecânicas condicionam as semioses em desenvolvimento nessa relação, que é parcialmente controlada pelo próprio usuário da mídia.

Dentro dessa estrutura formal, as mecânicas comunicam as regras para o jogador, oferecendo as ferramentas para que os objetivos possam ser alcançados, ao mesmo tempo que delimita a variedade de operações disponíveis nessa interação. Consequentemente, a percepção das regras, sua interpretação e a posterior tomada de atitude pelo usuário acontecerão dentro dos limites das mecânicas. Desse modo, elas carregam as mensagens das regras para o jogador ao delimitar as possíveis maneiras de compreender essas normas, agir sobre elas e atingir seus objetivos finais. A partir desse "contrato" entre os dois, todos os inputs realizados pelo interator, que agem como mensagens direcionadas às regras, serão mediados pelas mecânicas

Nesse sentido, jogadores configuram suas interpretações do cenário, além de todos seus elementos visuais, sonoros e hápticos, a partir das mecânicas praticáveis em concordância com suas regras. A experiência lúdica vincula-se às suas mecânicas e seu estilo de jogabilidade, gerando signos multicódigos tanto dos elementos ficcionais quanto das regras.

Em continuidade a ideia de que as mecânicas veiculam mensagens e as moldam de acordo com os modos de ação determinados por elas, ocorre também uma relação direta delas com o mundo externo ao game, seja por meio de sua ligação com as materialidades envolvidas na criação de jogos e na experiência lúdica ou por meio de alegorias ou representações de elementos e atividades características do universo sociocultural em que estão inseridas. 


\section{midiätica@e}

Os aspectos materiais que envolvem uma experiência de jogo, sejam as possibilidades e limitações técnicas de softwares empregados no game design, as condições do espaço onde as partidas ocorrem ou os dispositivos utilizados para interagir com o game influenciam tanto a criação das mecânicas quanto o modo como elas serão percebidas pelos jogadores. Desse modo, as mecânicas e, consequentemente, as mensagens delineadas a partir delas, têm seus processos de significação vinculados às materialidades implicadas durante todo o curso de um jogo, desde sua concepção até sua efetivação como experiência lúdica.

Visto que as mecânicas e seus significados se relacionam com o mundo externo ao game, elas têm potencial de operar, nessa medida, como alegorias ou representações de objetos fora de seu universo. As mecânicas podem ter como efeito se referir a um determinado contexto sociocultural e produzir significados e leituras dessa conjuntura baseados do próprio processo de jogo.

Almejamos, com esse artigo, observar mais de perto o papel das mecânicas na produção das semioses do jogo em que fazem parte como um dos elementos de sua estrutura formal. Para isso, levantamos questões e exemplos relacionados às maneiras como mecânicas veiculam mensagens com base na definição de modos de ação ao jogador, sua conexão com as materialidades envolvidas no processo lúdico e sua capacidade de atuar como alegorias e representações de objetos externos ao game. Nesse sentido, as mecânicas se constituem como componentes centrais para compreendermos melhor como os signos de um jogo são interpretados pelos jogadores e de que maneira as semioses são geradas.

\section{Referências}

APPERLEY, Thomas H. \& JAYEMANE, Darshana. A virada material dos game studies. In: Lumina, Juiz de Fora, v.11 n.1, abr. 2017. Disponível em: <https://lumina.ufjf.emnuvens.com.br/lumina/article/view/721/498>. Acesso em: 23 set. 2017.

BOGOST, Ian. Persuasive Games: the expressive power of videogames. Cambridge MA: The MIT Press, 2007.

Videogames and ideological frames. Popular communication: The International Journal of Media and Culture, Philadelphia, v. 6, n. 3, 2006. Disponível em: 


\section{midiäticales}

<http://www.tandfonline.com/doi/abs/10.1207/s15405710pc0403_2>. Acesso em: 26 jul 2017.

ESKELINEN, Markku. Towards Computer Game Studies. First person: new media as story, performance, and game. London: The MIT Press, 2004.

FLUSSER, Vilém. O mundo codificado: por uma filosofia do design e da comunicação.

CARDOSO, Rafael (Org.). Tradução: Raquel Abi-Sâmara. São Paulo: Cosac Naify, 2007.

HUIZINGA, Johan. Homo ludens: o jogo como elemento da cultura. Tradução de João Paulo Monteiro. São Paulo: Perspectiva, 2010.

JENKINS, Henry. Game design as narrative architecture. First person: new media as story, performance, and game.London: The MIT Press, 2004.

JUUL, Jesper. Half-real: video games between real rules and fictional worlds.

Cambridge: The MIT Press, 2005.

The game, the player, the world: looking for a heart of gameness. In: Level up: digital games research conference proceedings. Utrecht: Utrecht University, 2003. Disponível em: <http://www.jesperjuul.net/text/gameplayerworld>. Acesso em: 27 jul 2017.

KOLASINSKI, Eugenia M. Simulator sickness in virtual environments. Alexandria: U.S. Army Research Institute for the Behavioral and Social Sciences, 1995, 68 p.

KREMERS, Rudolf. Level design: concept, theory, and practice. Natick: A K Peters Ltd., 2009.

MANOVICH, Lev. The language of new media. Cambridge/London: The MIT Press, 2001.

MONTFORT, Nick; BOGOST, Ian. Racing the beam: The Atari Video Computer. Cambridge: The MIT Press, 2009.

MURRAY, Janet. Hamlet no Holodeck: o futuro da narrativa no ciberespaço. Tradução: Elissa Khoury Daher e Marcelo Fernandes Cuzziol. São Paulo: Itaú Cultural: Unesp, 2003.

RANHEL, João. O conceito de jogo e os jogos computacionais. In: SANTAELLA, Lucia \& FEITOZA, Mirna. Mapa do jogo: a diversidade cultural dos games. São Paulo: Cengage Learning, 2009, p. 3-22.

SALEN, Katie; ZIMMERMAN, Eric. Rules of play: game design fundamentals. Massachusetts: The MIT Press, 2004.

SIMON, Bart. Wii are out of control: bodies, game screens and the production of gestural excess. In: Loading, v. 3, n.4, 2009. Disponível em: <http://journals.sfu.ca/loading/index.php/loading/article/view/65/59>. Acesso em: 24 set. 2017. 


\section{culturae

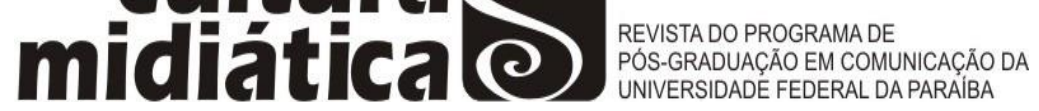

SWAIN, Chris. The mechanic is the message: how to communicate values in games through the mechanics of user. In: SCHRIER, Karen e GIBSON, David (orgs.). Ethics and game design: teaching values through play. Hershey/New York: Information Science Reference, 2010.

WARK, McKenzie. Gamer theory. Cambridge/ Massachusetts: Harvard University Press, 2007. 